Тарасенко Ивета Рудольфовна, Малашенко Михаил Сергеевич, Прокопенко Татьяна Ивановна, Таран Ирина Евгеньевна, Кудря Александр Дмитриевич

\title{
ФОРМИРОВАНИЕ ПРОФЕССИОНАЛЬНО-ЛИЧНОСТНЫХ КАЧЕСТВ СТУДЕНЧЕСКОЙ МОЛОДЕЖИ В ПРОЦЕССЕ ИХ ФИЗИЧЕСКОГО ВОСПИТАНИЯ
}

Статья посвящена исследованию механизма формирования профессионально-личностного развития и саморазвития студенческой молодежи в прочессе их физического воспитания в высиих учебных заведениях. Даниый процесс представляет собой специфическую самоорганизацио своего личностного образовательного и развивающего пространства, в котором он выступают субъектом профессионального становления и саморазвития личности. Модель профессионально-личностного развития студенческой молодежи включают в себя готовность к профессиональной деятельности, к развитию и саморазвитию. Отстода следует, что процесс физического воспитания в вузе способствует профессионально-личностному росту студенческой молодежси с опорой на внутренние источники саморазвития, в ситуачиях осмысления и выбора собственных личностных и профессиональных позиций.

Ключевые слова: формирование профессионально-личностных качеств, студенческая молодежь, физическое воспитание, профессиональное развитие, саморазвитие.

\section{Iveta Tarasenko, Mikhail Malashenko, Tatyana Prokopenko, Irina Taran, Alexander Kudrya FORMATION OF PROFESSIONAL AND PERSONAL QUALITIES OF STUDENTS IN THE PROCESS OF THEIR PHYSICAL EDUCATION}

The article is sanctified to research of forming mechanism professionally - personality development and caморазвития of student young people in the process of their P.E in higher educational establishments. This process is specific cамоорганизацию of the personality educational and developing space in that he come forward the subject of the professional becoming and camopasвumur of personality. The model of professionally-personality development of student young people is plugged in itselfreadiness to professional activity, to development and camopasвumuo. It is necessary from here, that the process of P.E in institution of higher learning assists the professionally-personality height of student young people with support on the internal sources of caморазвития, in the situations of comprehension and choice of own personality and professional positions.

Key words: Formation of professional and personal qualities, student youth, physical education, professional development, self-development.

Bведение / Introduction. Во многих зарубежных странах наиболее распространенными подходами в личностно-профессиональном становлении студенческой молодежи служит концепция, предусматривающая их профессиональное развитие.

Современная наука трактует понятие профессионализма студенческой молодежи как одну из форм развития личности, которая приобрела статус аксиоматического знания. При этом понятия («пофессионализм» и «развитие» рассматривается нами как взаимодополняющие понятия, что выражается в особой гиперреальности, которая соответствует понятию «профессиональное развитие». Понятие «профессиональное развитие» - это механизм профессионализации, посредством которого возможно решение определенного круга задач профессионального становления личности студента. (Профессиональное развитие) имеет тесную связь с общей онтогенетической эволюцией, характеризующей психические функции человека. 
Данная связь является двусторонней, где общее развитие психического уровня индивида условие начала его профессионального развития. В свою очередь, профессиональное развитие существенно влияет на общее развитие психических функций человека.

Maтериалы и методы / Materials and methods. Александр Григорьевич Асмолов рассматривает личность человека, в контексте индивидуализации выбирающего самостоятельно ту или иную деятельность, а порой и тот образ жизни, которые определят в дальнейшем его развитие.

«Профессиональное развитие» - это составная часть личностного развития студента, которое представляет собой процесс, в результате которого студенты приобретают бесценный опыт в своей профессиональной деятельности [1].

Профессиональное становление студента постоянно изменяется и при этом имеет несколько ступеней:

- первая ступень образования - это этап обучения в высшем учебном заведении;

- $\quad$ вторая ступень образования - этап послевузовского образования.

Данные ступени образования студенческой молодежи определяются либо как личностно-профессиональное развитие, либо как профессионально-личностное развитие.

Анализ данных терминов не выявил существенных различий в рассмотренных дефинициях «личностно-профессиональное развитие» и «профессионально-личностное», определяя их как процесс профессионального становления или роста, влекущий изменения в личности и деятельности бедущего специалиста. Главным результатом профессионально-личностного развития является активное качественное преобразование внутреннего мира специалиста, «приводящее его к принципиально новому строю и способу жизнедеятельности».

Профессионально-личностное развитие педагога определяется ролью, которую играют компоненты в личной регуляции деятельности.

В личной регуляция деятельности студенческой молодежи в процессе физического воспитания имеют большое значение следующие компоненты:

- профессиональная компетентность;

- операционально-технологическая готовность к профессиональной деятельности;

- творческий потенциал;

- интеллигентность;

- самосознание личности.

При этом первая ступень педагогического становления студента в высшем учебном заведении характеризуется сущностью профессионального и личностного развития педагога и основным ее содержанием становления студенческой молодежи, суббъектом их профессиональной и педагогической деятельности, которая предполагает овладение всем спектром ролей, позиций и функций, которые свойственны педагогической профессии в современных условиях [5].

Автор, в свою очередь, выделил следующие компоненты личностно-профессионального развития педагога по физической культуре:

- регулирующий;

- стабилизирующий;

- преобразующий.

Основными содержательными характеристиками этих компонентов выступают психологические новообразования в интегральной деятельности современного педагога:

- профессиональная идентичность;

- профессиональная компетентность;

- профессиональные качества;

- индивидуально-творческий стиль педагогической деятельности. 
Базовыми характеристиками личностно-профессионального развития студентов в высших учебных заведениях физической культуры и спорта определены следующие:

- профессионально-педагогическая направленность;

- инновационная профессионально-педагогическая позиция;

- творческая готовность к профессионально-педагогической деятельности [2].

Поскольку личностно-профессиональное развитие человека происходит в течение всей жизнедеятельности, то изменения проявляются:

- в развитой способности прогнозировать деятельность и ее результаты;

- моральной ответственности;

- чувствах достоинства;

- совести;

- духовности;

- проявлении чести;

- знании дела

- творчестве;

- умении рисковать.

Модель профессионально-личностного развития студенческой молодежи в процессе физического воспитания включают в себя готовность:

- $\quad$ к профессиональной деятельности;

- развитию и саморазвитию.

Результаты и обсуждение / Results and discussion. Исследования процесса физического воспитания студентов позволяют сформулировать определение профессионального и творческого развития студенческой молодежи высших учебных заведений. Данная формулировка определяет интегративное, многоуровневое и многокомпонентное образование, являющееся одной из важнейших особенностей личности студента, его стремление к саморазвитию и самосовершенствованию, творческий труд, его социальная активность [4].

Таким образом, несмотря на различные содержательные компоненты профессионально-личностного развития, выделенные авторами, они могут раскрываться специалистами через овладение ими опытом самоопределения, самовыражения, самореализации, согласованности индивидуальности и профессиональной подготовки. В этой связи особое значение приобретает личностное принятие педагогом саморазвития как особого вида деятельности.

Механизм профессионального и личностного развития и саморазвития студенческой молодежи в процессе физического воспитания представляет собой специфическую самоорганизацию своего личностного образовательного и развивающего пространства, в котором он выступают субъектом профессионального становления и саморазвития личности.

В то же время происходит процесс:

- выработки авторской педагогической системы;

- принятия и освоения содержания и технологий современного педагогического образования;

- выработки индивидуального и творческого профессионального почерка.

Профессиональный рост студенческой молодежи в процессе их физического воспитания может быть реализован посредством:

- приобщения их к определенным сферам и формам труда;

- приобщения к социально значимому опыту;

- у усвоения общественно значимого производственного опыта.

В процессе физического воспитания профессиональное и личностное развитие студенческой молодежи определяется внутренней их активностью, ответственным отношением к себе и к будущей профессиональной деятельности. 
При этом решаются задачи: культуросообразности; познавательности; морально-нравственные; коммуникативные; двигательные

Под влиянием данных задач происходит процесс развития личностных и профессиональных качеств и свойств, принимающих участие в обеспечении самореализации в повседневной учебной и профессиональной деятельности студента [3].

Педагогический процесс формирования профессиональных и личностных качеств студенческой молодежи в процессе их физического воспитания в высшем учебном заведении предусматривает взаимодействие личностей. В связи с этим созидающей в профессионально-личностном развитии будущего педагога в области физической культуры и спорта будет возможность его выступать в роли участника процесса обучения. Сущностью профессионального и личностного развития педагога и основным ее содержанием является процесс физического воспитания через профессионально педагогическую деятельность, которая предусматривает овладение всем спектром ролей, функций, и позиций, которые приемлемы в педагогической профессии в современных условиях $[1,4]$.

Процесс профессионально-личностного развития педагога происходит ступенчато, имеет свои закономерности в последовательности развертывания, обусловленные возрастными особенностями и логикой совершаемых изменений. Особенно активно профессионально-личностная подготовка происходит в высшем учебном заведении.

Заключение / Conclusion. Таким образом, в результате нашего исследования мы пришли к выводу, что формирование профессионально-личностных качеств студентов в высшем учебном заведении в процессе их физического воспитания происходит благодаря развитию личности как творца своей жизни, когда образование готовит ее к субъектной деятельности, формирует стремление к осмысленным поступкам, сознательному выбору своих жизненных позиций. Отсюда следует, что процесс физического воспитания в вузе способствует профессионально-личностному росту студенческой молодежи с опорой на внутренние источники саморазвития в ситуациях осмысления и выбора собственных личностных и профессиональных позиций. Такой подход определяет условия формирования концепции психолого-педагогического сопровождения профессиональной подготовки педагогов физической культуры.

\section{ЛИТЕРАТУРА И ИНТЕРНЕТ-РЕСУРСЫ}

1. Джавахов А. В. Формирование профессионального педагога посредством физической культуры / А. В. Джавахов, М. С. Малашенко, Д. Г. Гладких и др. // Актуальные вопросы права и правоприменения: сборник материалов Всероссийской научно-практической конференции. Ставрополь, 2017. C. $239-247$.

2. Козенко Е. Ю., Прокопенко Т. И., Кудря А. Д. Современный процесс модернизации системы физической культуры в системе высшего образования // Общество и личность: гуманистические тенденции в развитии современного общества: сборник научных статей преподавателей, обучающихся вузов, научно-практических работников. Ставрополь, 2017. С. 509-512.

3. Кудря А. Д., Шульженко А. В., Буклова Н. И. Социально-педагогические аспекты физического воспитания студентов // Актуальные проблемы науки: от теории к практике: материалы II Всероссийской научно-практической конференции / под ред. Ю. П. Кожаева, О. Ю. Зевеке. М., 2015. С. 215-217.

4. Кудря А. Д. Условия развития и совершенствования навыков психорегуляции и саморегуляции у студентов факультета физической культуры / А. Д. Кудря, А. В. Джавахов, Т. И. Прокопенко, Д. Г. Гладких // Социально-экономические, психолого-педагогические, философские и правовые аспекты развития общества: сборник материалов Всероссийского научно-практического круглого стола. Ставрополь, 2016. С. 57-59.

5. Таран И. Е. Профессиональная подготовка педагога в современных условиях /И. Е. Таран, А. А. Айрапетова, М. С. Малашенко, А. Д. Кудря, Е. Ю. Козенко // Научно-методические проблемы профессиональной и служебной подготовки в органах внутренних дел России: сборник материалов Всероссийской научно-практической конференции. Ставрополь, 2017. С. 353-362. 


\section{REFERENCES AND INTERNET RESOURCES}

1. Dzhavahov A. V. Formirovanie professional'nogo pedagoga posredstvom fizicheskoj kul'tury (Formation of professional teacher through physical culture) / A. V. Dzhavahov, M. S. Malashenko, D. G. Gladkih i dr. // Aktual'nye voprosy prava i pravoprimeneniya: sbornik materialov vserossijskoj nauchno-prakticheskoj konferencii. Stavropol', 2017. S. 239-247.

2. Kozenko E. Yu., Prokopenko T. I., Kudrya A. D. Sovremennyj process modemizacii sistemy fizicheskoj kul'tury v sisteme vysshego obrazovaniya (Modern process of modernization of the system of physical culture in the system of higher education) // Obshchestvo i lichnost': gumanisticheskie tendencii v razvitii sovremennogo obshchestva: sbornik nauchnyh statej prepodavatelej, obuchayushchihsya vuzov, nauchnoprakticheskih rabotnikov. Stavropol', 2017. S. 509-512.

3. Kudrya A. D., Shul'zhenko A. V., Buklova N. I. Social'no-pedagogicheskie aspekty fizicheskogo vospitaniya studentov (Socio-pedagogical aspects of physical education students) // Aktual'nye problemy nauki: ot teorii k praktike: materialy II Vserossijskoj nauchno-prakticheskoj konferencii / pod red. Yu. P. Kozhaeva, O. Yu. Zeveke. M., 2015. S. 215-217.

4. Kudrya A. D. Usloviya razvitiya i sovershenstvovaniya navykov psihoreguly acii i samoregulyacii u studentov fakul'teta fizicheskoj kul'tury (Conditions for the development and improvement of skills of psihoneurozy and self-regulation among students of faculty of physical culture) / A. D. Kudrya, A. V. Dzhavahov, T. I. Prokopenko, D.G. Gladkih // Social'no-ekonomicheskie, psihologo-pedagogicheskie, filosofskie i pravovye aspekty razvitiya obshchestva: sbornik materialov Vserossijskogo nauchno-prakticheskogo kruglogo stola. Stavropol', 2016. S. 57-59.

5. Taran I. E. Professional'naya podgotovka pedagoga v sovremennyh usloviyah (Professional training of teachers in modern conditions) / I. E. Taran, A. A. Ajrapetova, M. S. Malashenko, A. D. Kudrya, E. Yu. Kozenko // Nauchno-metodicheskie problemy professional'noj i sluzhebnoj podgotovki v organah vnutrennih del Rossii: sbornik materialov vserossijskoj nauchno-prakticheskoj konferencii. Stavropol', 2017. S. $353-362$.

\section{СВЕДЕНИЯ ОБ АВТОРАХ}

Тарасенко Ивета Рудольфовна, кандидат педагогических наук, доцент кафедры физической культуры для гуманитарных и естественнонаучных специальностей, факультета физической культуры института образования и социальных наук СКФУ. E-mail: kfk-sgu@yandex.ru

Малашенко Михаил Сергеевич, кандидат социологических наук, старший преподаватель кафедры физической подготовки и спорта Ставропольского филиала Краснодарского Университета МВД России. E-mail:kudrya.sasha70@mail.ru

Прокопенко Татьяна Ивановна, кандидат педагогических наук, доцент, заведующий кафедрой физической культуры СКФУ. E-mail: kfk-sgu@yandex.ru

Tаран Ирина Евгеньевна, старший преподаватель кафедры физической культуры для технических специальностей, факультета физической культуры Института образования и социальных наук СКФУ. E-mail: kfk-sgu@yandex.ru

Кудря Александр Дмитриевич, кандидат педагогических наук, доцент кафедры социальных, гуманитарных и экономических дисциплин, ЧПОУ. МК «Авиценна», г. Ставрополь. E-mail:kudrya.sasha70@mail.ru

\section{INFORMATION ABOUT AUTHORS}

Iveta Tarasenko, candidate of pedagogical Sciences, associate Professor of the Department of physical culture for Humanities and natural sciences, faculty of physical culture of the Institute of education and social Sciences of NCFU. E-mail: kfk-sgu@yandex.ru

Mikhail Malashenko, candidate of sociological Sciences, senior lecturer, Department of physical training and sports of Stavropol branch of Krasnodar University of the Ministry of internal Affairs of Russia. E-mail: kudrya.sasha70@mail.ru

Tatyana Prokopenko, candidate of pedagogical Sciences, associate Professor, head of the Department of physical culture of NCFU. E-mail: kfk-sgu@yandex.ru

Irina Taran, senior lecturer of the Department of physical culture for technical specialties, faculty of physical culture, Institute of education and social Sciences of NCFU. E-mail: kfk-sgu@yandex.ru

Aleksandr Kudrya, candidate of pedagogical Sciences, associate Professor of social, humanitarian and economic disciplines, NOU Avitsenna, Stavropol. E-mail: kudrya.sasha70@mail.ru 